\title{
CAUSAS ATMOSFÉRICAS DE DOS DESCOMUNALES LLENAS EN LA RAMBLA DE NOGALTE (CUENCA DEL SEGURA)
}

\author{
Antonio Gil Olcina \\ Instituto Interuniversitario de Geografía \\ Universidad de Alicante
}

\section{RESUMEN}

La Rambla de Nogalte solo supera su condición endorreica cuando, con motivo de aguaceros copiosos e intensos, experimenta fuertes crecidas; bifurcardas sus aguas, acaban por llegar parcialmente, a través de ramblas intermedias, a los ríos-ramblas Guadalentín y Almanzora. Con su cuenca de recepción en el macizo bético de la Sierra de las Estancias y superficie vertiente total de $139 \mathrm{~km}^{2}$, posee un funcionamiento torrencial acabado y prototípico.

Dicha rambla ha registrado en menos de medio siglo, período de retorno muy inferior al estadísticamente esperado, dos monstruosas y casi inconcebibles avenidas, los días 19 de octubre de 1973 y 28 de septiembre de 2012, con puntas estimadas, a la altura de Puerto Lumbreras, en 1.974 y $2.489 \mathrm{~m}^{3} / \mathrm{s}$ respectivamente; las mayores de que hay noticia histórica para este tipo de cursos en la cuenca del Segura. Una y otra tuvieron por causa desencadenante y básica dos diluvios vinculados a "gotas de aire frío» acompañadas de situaciones en superficie excepcionalmente idóneas para propiciar focalizaciones de precipitaciones muy cuantiosas y de elevada concentración horaria.

Palabras clave: Rambla, «gotas frías», diluvios otoñales, avenidas colosales

\section{ABSTRACT}

Atmospheric causes of two extreme floods in the Rambla de Nogalte Segura basin)

The Rambla de Nogalte only deviates from its endorheic nature when torrential rain causes severe floods; then, its waters split and some flows along intermediate watercourses to eventually reach the Guadalentín and Almanzora rivers. With a catchment area located in the Baetic massif of the Sierra de las Estancias and covering a total surface area of $139 \mathrm{~km}^{2}$, the Nogalte fundamentally operates as prototypical flood drainage. 
In less than half a century, a much lower return period than statistically expected, this watercourse has registered two enormous and almost unimaginable floods, on October 19, 1973, and September 28, 2012, with estimated peak flows at Puerto Lumbreras of 1,974 and 2,489 $\mathrm{m}^{3} / \mathrm{s}$ respectively; the highest ever recorded for this type of watercourse in the Segura Basin. Both events were triggered by torrential rain associated with a sudden drop in temperature accompanied by surface conditions that were exceptionally conducive to creating very heavy local rainfall with a high hourly concentration.

Keywords: Rambla, sudden drop in temperature, torrential autumn rainfall, extreme floods

La superficie vertiente a la Rambla de Nogalte se extiende $139 \mathrm{~km}^{2}$ por los términos de Vélez Rubio, Puerto Lumbreras y Lorca. Se trata de una cuenca semiendorréica, puesto que solo deja de ser endorreica cuando su salida, con ocasión de algún aguacero copioso e intenso, cobra entidad suficiente para que sus aguas, muy crecidas, rebasen el umbral llamado, significativamente, «Caballón de la Hoya»; en dicha circunstancia, la avenida se bifurca, a la altura de Redón y Venta de Ceferino, de modo que una parte del caudal, sumado al de la Rambla de Vilerda, afluye a la Rambla de Biznaga, tributaria del Guadalentín; el resto de la llena llega a la Rambla de los Charcones, que avena derrames de la Sierra de Almenara a la Depresión Prelitoral y penetra luego, rebautizada como Rambla de Nogantes, en el municipio almeriense de Pulpí; para después de cambiar nuevamente su nombre por el de Rambla de Canalejas, y recibir a la de Guazamara, afluir, por la margen izquierda, en término de Cuevas del Almanzora, a este río-rambla. Si la avenida no excede el referido umbral, tampoco los caudales epigeos de la Rambla de Nogalte acaban en el Mediterráneo; si la llena no es bastante poderosa, como sucede las más de las veces, la circulación en la susodicha cuenca no es exorreica, sino endorreica. Funcionamiento este que auspicia y potencia la infiltración del agua en las gravas y arenas del lecho, favoreciendo el multisecular y, durante siglos, vital aprovechamiento de subálveas, que terminaría reflejándose en la toponimia, con el cambio de nombre de la propia localidad beneficiaria del indicado afloramiento, que pasó de llamarse Nogalte a Puerto Lumbreras, topónimo que aúna las dos referencias esenciales de encrucijada de caminos y existencia de una foggara o galería de captación con pozos de limpieza y aireación llamados «lumbreras».

Situada la cuenca semiendorreica de la Rambla de Nogalte entre dos de rango superior (Guadalentín y Almanzora), cuando la avenida o llena trueca funcionamiento endorreico por exorreico, sus aguas se dividen entre ambas, al llegar a las ramblas de Biznaga y Charcones-Nogantes-Canalejas, respectivamente. Más en detalle, la subcuenca superior de la Rambla de Nogalte queda encuadrada por las divisorias con las superficies vertientes al Río Corneros o 
Vélez, una de las ramas madres del Guadalentín en el Estrecho de Puentes, y las correspondientes a las Ramblas de Albox y Huércal-Overa, en la red del Almanzora. Las subcuencas media e inferior, es decir, el tramo del reborde de la Depresión Prelitoral y el sector de esta, vienen ceñidas por las vertientes de las ramblas de Vilerda, al oeste, y Casarejos-Béjar al este, pertenecientes una y otra al Sistema Guadalentín-Biznaga. Desde los $1.060 \mathrm{~m}$ de altitud inicial, en las cercanías del vértice de Tonosa $(1.132 \mathrm{~m})$, la Rambla de Nogalte desciende a la cota 360, que es la de su amplio cono de deyección en la Depresión Prelitoral; ese descenso es fruto de un recorrido de $30 \mathrm{~km}$ con pronunciado declive longitudinal del 25\%. En dicho trayecto, que principia en el corazón de la Sierra de las Estancias, a menos de $5 \mathrm{~km}$ del vértice culminante (Estancias, $1.467 \mathrm{~m}$ ) y, como se ha indicado, a mayor proximidad del secundario de Tonosa, el curso se encamina, inicialmente, al noroeste, para cambiar pronto de rumbo, y dirigirse al suroeste, penetrando con esta dirección en el término murciano de Puerto Lumbreras, cuyo núcleo urbano se extiende por su margen izquierda.

La subcuenca superior, que discurre por el macizo bético expresado, atravesando un espacio anfractuoso y abrupto, constituye una auténtica cuenca de recepción torrencial, que alimentan eventualmente un conjunto de barrancos, ramblas y ramblizos; en especial, por su margen derecha, a la que llegan las ramblas de Losilla, Zapillo, Pradico, Majuelos, Cárdena y Talancón. Es de resaltar que en este amplio sector montañoso los declives, superiores al 30\%, imprimen, con ocasión de aguaceros copiosos e intensos, gran rapidez a la circulación epigea y favorecen, extraordinariamente, el aflujo a la Rambla de Nogalte de la escorrentía que se descuelga veloz por las empinadas vertientes de una cabecera,-casi dos terceras partes de la cuenca-, que asume máximo protagonismo en la génesis de sus fabulosas, casi inconcebibles, avenidas. Subrayemos asimismo la abundante presencia, en esta cuenca de recepción, de materiales metamórficos (filitas, esquistos, cuarcitas, micaesquistos) muy fisurados e intensamente alterados, que, sumados a los materiales liberados por el rompimiento y laboreo agrícola de los secanos, despojados de vegetación, a favor de condicionamientos climáticos bien propicios, proporcionan en las crecidas cargas límite enormes.

En las mayores llenas de la Rambla de Nogalte, destaca, y mucho, el elevado porcentaje de aporte sólido (estimado en el $40 \%$ para la de 19 de octubre de 1973), dato sobresaliente, incluso en una cuenca donde el curso mayor-Segura, al margen- se nombre con el arabismo de Guadalentín: literalmente, «río del fango». Esa ingente carga límite resulta de la conjunción de un conjunto de factores; primordialmente, potencia de la corriente, calibre de los materiales transportados y adherencia de los mismos. En cuanto a la primera, es de notar el sustancial incremento de velocidad que proporciona a las crecidas aguas la acusada pendiente media (25\%) con que la Rambla desciende de la Sierra de las 
Estancias a la Depresión Prelitoral; el brusco descenso de aquella, que pasa de 25 a $10 \%$ en dicha llanura, incapacita a la corriente para seguir transportando la totalidad de la carga, de modo que deposita y edifica un dilatado cono de deyección. Y, como se ha anticipado, condicionamientos asimismo favorables constituyen la existencia de roquedos muy cuarteados, de fácil fragmentación, y la fuerte agresividad erosiva del clima, semiárido de raigambre mediterránea y verano seco de filiación subtropical; en efecto, a la pérdida de compacidad y adherencia, motivada por la sequedad estival, suceden, en los supuestos considerados, episodios de lluvias otoñales copiosas e intensas. Subrayemos, por último, que el calibre muy mayoritario de materiales transportables, intensamente fragmentados, detríticos, es muy inferior al que defina la competencia de la corriente de agua en estas ocasiones; y, gracias a ello, la crecida puede transportar una carga muy superior a la posible si los materiales movilizados fuesen de mayor tamaño y peso; dado que, a igualdad de otras condiciones, la carga límite aumenta en la medida que es menor el tamaño de los materiales acarreados.

En un intervalo relativamente corto, incomparablemente por bajo de los períodos de retorno estadísticos, concretamente en los treinta y nueve años que median entre el 19 de octubre de 1973 y el 28 de septiembre de 2012, la Rambla de Nogalte registró, en las fechas indicadas, las dos mayores llenas de que hay noticia histórica, con puntas de avenida que rondaron o excedieron los 2.000 $\mathrm{m}^{3} / \mathrm{s}$. La primera, la de «San Pedro de Alcántara», que devastó la localidad de Puerto Lumbreras y ocasionó, en total, 87 víctimas, es la crecida más mortífera de las acaecidas el siglo xx en la cuenca del Segura; las actuaciones hidráulicas de la Confederación Hidrográfica del Segura de resultas del desastre, en especial el encauzamiento de la Rambla a su paso por el núcleo de Puerto Lumbreras, incrementando mucho la capacidad de desagüe anterior, evitaron la repetición de la catástrofe en la Avenida de San Wenceslao, un episodio de características similares y parecida magnitud. Los epígrafes siguientes analizan ambos fenómenos meteorológicos.

\section{FACTORES DE INESTABILIDAD ATMOSFÉRICA}

Premisa indispensable de los diluvios tardoestivales objeto de consideración es el aflujo de aire con elevada humedad específica en superficie, aportado, habitualmente, por viento de componente este y procedencia mediterránea, mar donde en esa época del año imperan condiciones térmicas, tanto en sus aguas como del aire en contacto con ellas, proclives a un proceso de evaporación muy activo e intenso. Sin embargo, con ser necesaria esa característica del aire ascendente, en modo alguno lleva aparejadas automáticamente precipitaciones torrenciales; para que estas se produzcan deben concurrir asimismo otros factores. 
Entre ellos, ocupa un lugar, sin duda, preferente la irrupción de aire anormalmente frío en los niveles superiores de la troposfera; estas penetraciones, que implican un marcado descenso latitudinal de las isotermas de altitud e isohipsas, particularmente manifiesto en la superficie de altura geopotencial de $500 \mathrm{hPa}$, se traducen en la aparición de una vaguada, capaz o no de evolucionar hacia la formalización de una depresión fría en altitud, baja desprendida o depresión aislada en niveles altos (D.A.N.A.). Es de destacar que dicho estadio no resulta imprescindible para el estallido de colosales aguaceros, que se desencadenan también en presencia de una vaguada con entidad suficiente.

Este destacado protagonismo de las advecciones de aire frío en altitud obedece a varios motivos. En principio, generan inestabilidad atmosférica por incremento del gradiente térmico estático en la vertical, que puede alcanzar entonces valores de 0,6 a $0,8 \% 100 \mathrm{~m}$ entre las topografías absolutas de $500 \mathrm{hPa}$ (aire frío) y $850 \mathrm{hPa}$ (aire cálido y húmedo supramediterráneo). Al conjugarse esta exageración de gradiente con una corriente ascendente de aire con elevada relación de mezcla y sumamente inestable, se amplía y potencia el efecto de disparo. La liberación de energía latente subsiguiente a la condensación desde poca altitud, proporciona valores muy reducidos al gradiente pseudoadiabático, y permite desplazamientos convectivos de nueve a diez kilómetros, hasta la misma tropopausa, interesando la totalidad de la troposfera con enormes nubes de desarrollo vertical, gigantescos cumulonimbos de la especie pilleus o capillatus.

Cabe resaltar asimismo como la inestabilidad potencial que comporta la advección de estas masas de aire conducidas por vientos del primero y segundo cuadrantes (levantes, gregales y sirocos) y el camino que abre al disparo en la vertical la exageración de gradiente, requieren el efecto de gatillo que suele ejercer el relieve, al iniciar el despegue por convección forzada. La incidencia del relieve resulta particularmente trascendente si el gradiente horizontal de presión en superficie es débil, de modo que los vientos resulten flojos; y así suele suceder con relieves isobáricos poco contrastados, como los que nos ocupan. Caracterizada la primera de las situaciones, en superficie y para el área afectada, por hallarse englobada en una extensa y nada profunda área depresionaria relativa (1016-1012 hPa), con levante moderado la madrugada del 19 de octubre de 1973; no difería sustancialmente la segunda, también con bajas presiones relativas (1012-1008 hPa), y amplio pantano barométrico sobre la mitad meridional de la Península Ibérica, con levante débil, calma casi en el referido espacio. También la acción combinada de determinadas formas de relieve y sus pendientes repercute en la pluviometría; a los efectos que ahora interesan, han de subrayarse focalizaciones muy intensas de precipitaciones, con vientos llovedores del este, en la Sierra de las Estancias, por su ubicación en el reborde montañoso interior de la Depresión Prelitoral, la propia configuración de este macizo bético y el modelado del mismo por la agresividad erosiva, aerolar $y$, 
sobre todo, lineal del clima semiárido de raigambre mediterránea y verano seco de filiación subtropical, causante de numerosos barrancos que encajan dichos flujos del este y originan en ellos convergencias por confluencia.

No resulta ocioso reiterar la singular trascendencia del Mediterráneo como enorme reservorio de agua y calorías y, según los casos, hogar o posada de masas de aire, a las que confiere su impronta térmica y, en función de la naturaleza de aquellas, época del año y permanencia, una determinada carga higrométrica, a veces enorme, como en los dos episodios de referencia, y capaz de alimentar mortíferos diluvios. En este sentido, son de destacar igualmente los desfases térmicos mar-tierra, que muy acusados en otoño e invierno, alcanzan su máximo valor en octubre, mes que, junto a la segunda mitad de septiembre y primera de noviembre, por el juego combinado de elevadas relaciones de mezcla, mayores gradientes térmicos horizontales y eventual incremento de los verticales, concentran una gran mayoría de los aguaceros causantes de las peores inundaciones del Guadalentín-Segura.

DOS «APERTURAS DE LAS CATARATAS DEL CIELO» TARDOESTIVALES

A veces, en el Sureste Ibérico, los verbos «diluviar» o «jarrear», cuya acepción común es la de «llover copiosamente», resultan insuficientes para expresar la magnitud e intensidad de determinados episodios pluviométricos, ya que entonces no «llueve a cántaros», sino «a mares», se dice, por ello, «que se abren las cataratas del cielo». Y esta expresión conviene, sin duda, a lo acecido, en la Sierra de las Estancias, los días 19 de octubre de 1973 y 28 de septiembre de 2012, cuando la Rambla de Nogalte registró sendas llenas con puntas casi inconcebibles, en el entorno de $2.000 \mathrm{~m}^{3} / \mathrm{s}$.

A las dos situaciones atmosféricas correspondientes les convienen, con carácter general, las denominaciones de embolsamiento frío, depresión fría en altitud, baja desprendida o depresión aislada en niveles altos (D.A.N.A.); todas ellas expresiones de gran magnitud o extensión, que incluyen otras varias de mayor comprensión, más ajustadas y precisas. Así, en los casos que nos ocupa, no existe inconveniente alguno, todo lo contrario, para emplear el concepto de «gota de aire frío», en el sentido prístino o acepción originaria que Scherhag diera al término Kaltluftropfen. Se trata, en efecto, de depresiones marcadas en las troposferas media y superior, que, en estos casos, coinciden con áreas depresionarias relativas nada profundas, de naturaleza térmica, que desbordan el territorio africano. A tenor de esta definición, rasgos básicos son los siguientes: presencia, al menos, de una isohipsa cerrada en la topografía absoluta de 500 $\mathrm{hPa}$; el aire a más baja temperatura viene a coincidir con el núcleo o corazón de la depresión en altitud; tampoco falta, en uno y otro caso, una isohipsa de espesor cerrada en la topografía relativa o mapa de altura 1000/500 hPa. Es de recordar, 
y subrayar, que «gota de aire frío» no es, en modo alguno, sinónimo de aguaceros copiosos e intensos; la presencia de los mismos en estos dos casos concretos resulta indisociable de la presencia en superficie de vientos llovedores del este, que conducen aire supramediterráneo con las características indicadas; sin que falten en ellos matices propios dignos de mención.

La topografía de la superficie de $500 \mathrm{hPa}$ a las 00h (T.M.G.) de $19 \mathrm{de}$ octubre de 1973 muestra un embolsamiento de aire frío en el seno de una vaguada retrógrada que abarca la totalidad de la Península Ibérica. Con las isohipsas de 5.640 y 5.700 $\mathrm{m}$ cerradas, el centro de esta baja desprendida o depresión fría en altitud, con aire a $-20^{\circ} \mathrm{C}$, se ubica en el suroeste peninsular; mientras el sureste queda bajo las isohipsas de 5.700 y $5.760 \mathrm{~m}$, sector en el que actúa el mecanismo de divergencia por difluencia que configuran la isohipsa externa de la baja y la más interior, no cerrada, de la vaguada; la situación descrita perduraba a las $12 \mathrm{~h}$. (T.M.G.). A esas horas, el

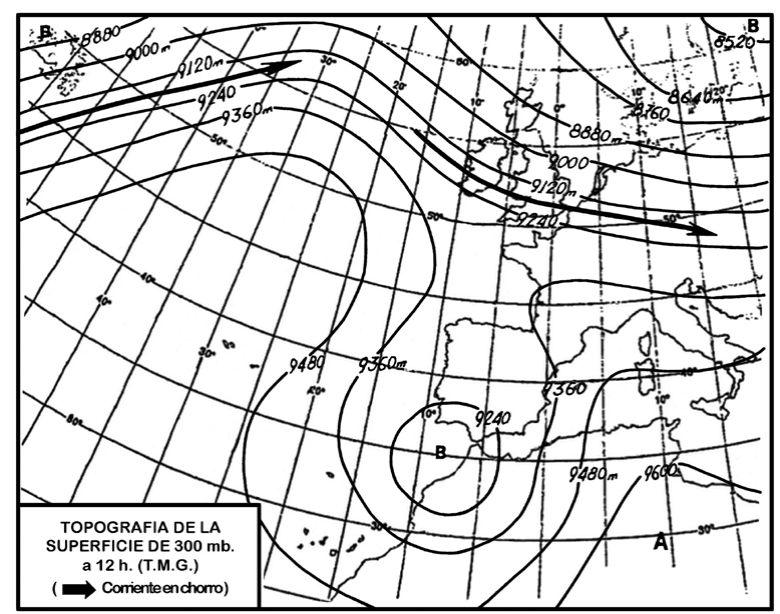

Fig. 1. Luego de un episodio de baja circulación zonal, con corriente en chorro meandrizante y débil, desvanecida a la postre; el flujo del oeste, articulado en torno a jet-stream vigoroso, a más de $150 \mathrm{~km} / \mathrm{h}$, circula a latitudes muy superiores a las de la Península Ibérica. Esta queda englobada por una vaguada, cuya isohipsa interior, estrangulada, ha configurado una depresión fría o baja desprendida.

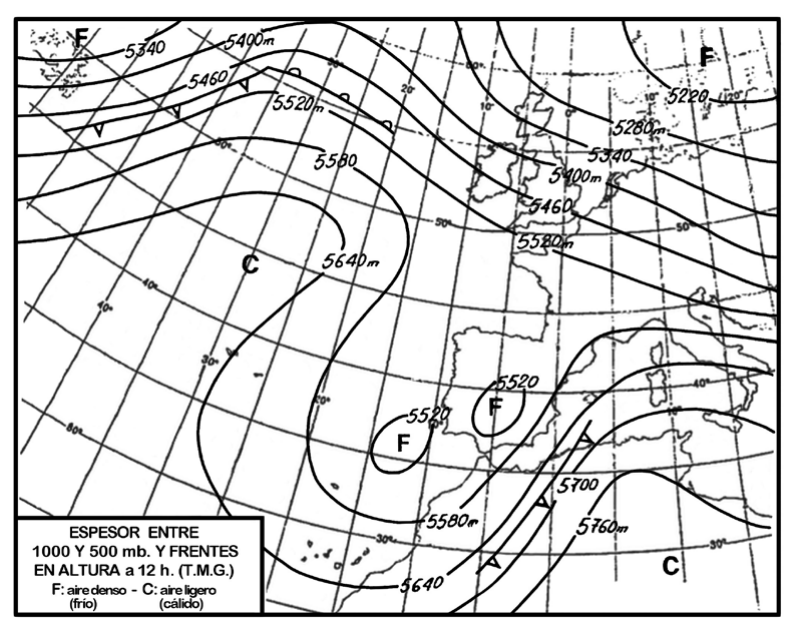

Fig. 2. En relación con el embolsamiento de aire frío, resultante de la seclusión de dos isohipsas (5.640 y $5.700 \mathrm{~m})$ del interior de la vaguada, en la topografía absoluta de $500 \mathrm{mb}$ o $\mathrm{hPa}$, aparecen dos núcleos de aire frío en el mapa de altura $1.000 / 500 \mathrm{mb}$, cerrados uno y otro por la línea de espesor o isohipsa relativa de $5.520 \mathrm{~m}$. 


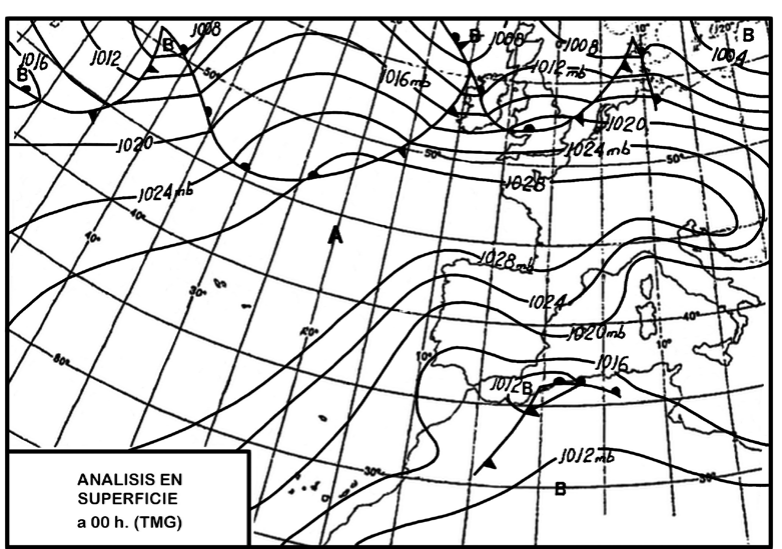

Fig. 3. La situación en superficie aparece dominada por un gran anticiclón de bloqueo, que desplaza hacia latitudes superiores la trayectoria de una familia de ciclones noruegos, mientras su borde meridional dirige hacia la fachada oriental de la Península Ibérica aire de procedencia mediterránea, conducido por viento de levante; rumbo coincidente con el del suave flujo que el sector septentrional de una vasta depresión relativa, centrada en el Sahara y de raigambre térmica, encamina al Sureste Ibérico. De notar es asimismo la existencia de una pequeña y nada profunda borrasca de estructura frontal en el Mar de Alborán, que actúa como área de rotación ciclónica y convergencia de vientos, favoreciendo su disparo en la vertical.

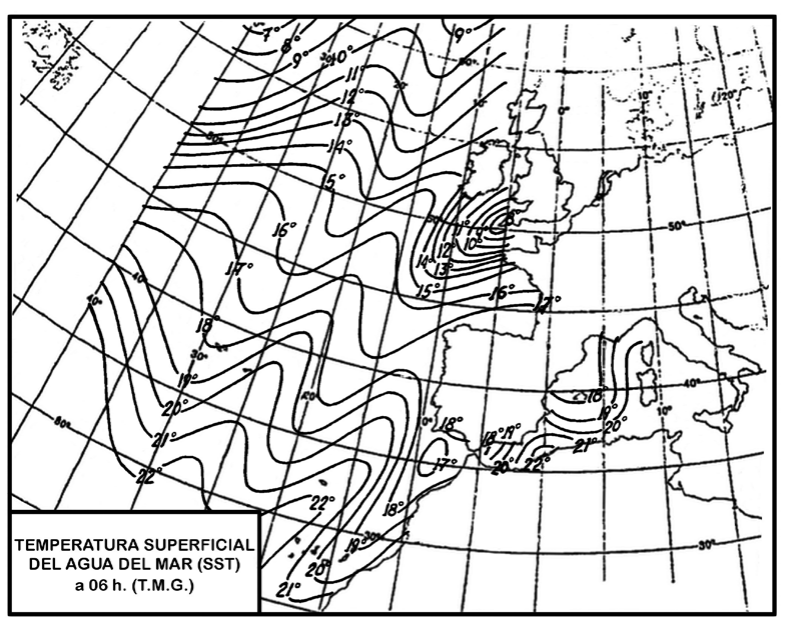

Fig. 4. Mapa de isotermas marinas superficiales que, merced a la inercia térmica de las aguas, registran, a las $06 \mathrm{TMG}, 22^{\circ} \mathrm{C}$ frente al Sureste Ibérico. Condiciones óptimas para transferir vapor de agua y enjugar el déficit hídrico de aire tropical continental en origen, proporcionándole así una elevada relación de mezcla. análisis en superficie destacaba un gran anticiclón de bloqueo, cuyo flanco o borde meridional ocasiona levante sobre la fachada oriental de España, rumbo este que es asimismo el del flujo suave que motiva para el sureste ibérico el sector septentrional de una extensa área depresionaria relativa de raigambre térmica, centrada en el Sahara, con isobaras bien distantes de $1016 \mathrm{y}$ $1012 \mathrm{hPa}$. El aire, tropical continental en origen, conducido por el flujo mencionado, se hallaba en inmejorables condiciones para enjugar el déficit hídrico en su amplio trayecto sobre aguas mediterráneas cuyas temperaturas superficiales, a las 06h. (T.M.G.), quedaban entre 20 y $22^{\circ} \mathrm{C}$. En suma, el aire, conducido por viento de levante, era relativamente cálido y poseía elevadas humedades específica y relativa, elevado potencial energético $y$ acusada inestabilidad. Al efecto de percusión ejercido, para su disparo en la vertical, por las sierras litorales y prelitorales, se añadió la existencia, como área de rotación ciclónica en el Mar de Alborán, de 
una pequeña borrasca de estructura frontal, con tan solo la isobara de $1012 \mathrm{hPa}$ cerrada a las $00 \mathrm{~h}$, a la que sumaría la de 1008 a las $12 \mathrm{~h}$.

En altitud, a la exageración de gradiente real que producía la llegada de aire a $-20^{\circ} \mathrm{C}$ a 5.640 $\mathrm{m}$, se incorporó también el efecto de trompa de succión, favorecedor del ascenso, que motivaba el susodicho mecanismo de divergencia por difluencia en delta. Por todo ello, concurrieron la serie de factores necesarios para desencadenar el

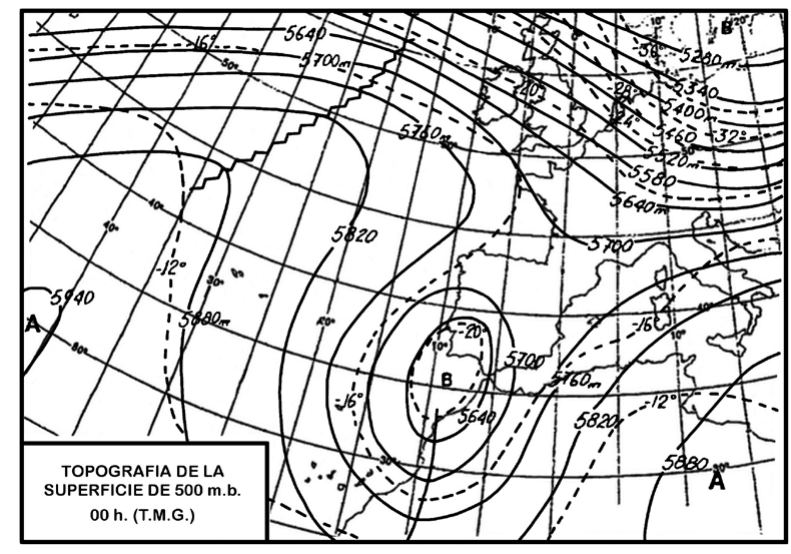

Fig. 5. Esta topografía absoluta muestra una depresión fría, baja desprendida o DANA, específicamente en este caso una "gota de aire frío" (Kaltluftropfen), entre cuya isohipsa exterior $(5.700 \mathrm{~m})$ y la interior de la vaguada $(5.760 \mathrm{~m})$ se configura una divergencia en delta por difluencia; este mecanismo, a modo de trompa de vacío, potencia la corriente ascendente de aire mediterráneo, a cuyas expensas se produjo el diluvio de 19 de octubre de 1973 en una extensa área meridional del Sureste Ibérico. diluvio, es decir: advección en superficie, conducido por viento de levante, de aire, tropical continental en origen, que había adquirido alta tensión de vapor en su trayectoria sobre las tibias aguas mediterráneas, y había experimentado así doble enriquecimiento, hídrico y energético; con ventaja térmica inicial respecto del aire circundante, saturado ya, o muy pronto por el enfriamiento adiabático inherente al ascenso, podía evolucionar, de manera inmediata con gradiente pseudoadiabático bien reducido. El disparo en la vertical de este aire sumamente inestable hasta el límite de la tropopausa, generando colosales cumulonimbos de la especie pillus o capillatus, gigantescas «nubes puestas en pie» que afectan todo el espesor de la troposfera, hallaba camino despejado por la exageración del gradiente real y el susomentado efecto dinámico de convergencia por confluencia.

Ese día, 19 de octubre de 1973, «se abrieron las cataratas del cielo», en el Sureste Ibérico, sobre las cuencas del Guadalentín, Almanzora y Rambla de Buñol, generando colosales avenidas; particularmente mortífera fue la monstruosa llena de la Rambla de Nogalte, que se abatió sobre Puerto Lumbreras y produjo en esta localidad 87 víctimas, al resultar insuficiente el cauce, constreñido por el caserío, para evacuar el colosal aluvión. En efecto, el ascenso de aire con muy alta relación de mezcla, sumamente inestable, hasta la misma tropopausa, evidenciado y visible por la génesis de gigantescas «nubes puestas en pie», colosales cumulonimbos que, rematados en formas de yunque a nivel 
de la susomentada discontinuidad, poseían todo el espesor de la troposfera, acabó originando un aguacero muy copioso e intenso: $173 \mathrm{~mm}$, volumen que cobra su entera significación relativa y perniciosidad si se considera que equivale al 70\% de la precipitación anual media en Puerto Lumbreras $(246 \mathrm{~mm})$, y se produjo básicamente en apenas tres horas. Semejante diluvio fue posible por la conjunción de condicionamientos atmosféricos propicios en superficie y altitud. Conditio sine qua non, es decir, requisito esencial e imprescindible fue la advección de aire supramediterráneo de crecida humedad específica y enorme potencial energético, consecuencia ambos de la transferencia al mismo, por las tibias aguas mediterráneas $\left(20-22^{\circ} \mathrm{C}\right.$, a las $\left.6.00 \mathrm{~h}\right)$, de ingentes cantidades de vapor de agua; dicho aire era conducido a tierra por viento de componente este, normal a las alineaciones montañosas costeras y prelitorales que, al producirse la convección forzada, lo disparaban en la vertical, a favor de la liberación de energía por el cambio de estado del agua atmosférica y de la exageración de gradientes reales en las troposferas media y alta e instalación de un campo de divergencia por difluencia, que potenciaba el ascenso por efecto de succión. Añadamos también la existencia de ciclogénesis en el Mar de Alborán, que configuró una borrasca, de reducida dimensión y poco profunda; pero capaz, aun con esas limitaciones, de favorecer, como área de rotación ciclónica y convergencia de viento, el citado disparo.

Una lluvia tan abundante e intensa, al precipitarse con violencia sobre suelos con escasa protección vegetal, resecos tras el verano, ocasionaba, de inmediato, el arrastre de cuantioso material detrítico en vertientes de pronunciadas pendientes. Así pues, bien pronto, el agua fangosa se concentraba en ramblizos, barrancos y ramblas, que de forma enteramente sincrónica, confluían en la cabecera de la Rambla de Nogalte, eficacísima cuenca de recepción torrencial; sector donde se gestan, como sucedió señaladamente en esta ocasión, crecidasrelámpago monogénicas, capaces de alcanzar, vertiginosamente, en tiempo muy reducido, puntas de avenida casi increíbles, que unen al crecidísimo aporte líquido el sólido que, con porcentajes inauditos sobre el total, transportan estas monstruosas avenidas torrenciales de carga límite y competencia elevadísimas. En el caso que nos ocupa, prototípico sin duda, el máximo instantáneo de la colada fangosa subió a $1.974 \mathrm{~m}^{3} / \mathrm{s}$, de los cuales 813 (41\% del total) eran arrastres sólidos, según estimaciones de la Confederación Hidrográfica del Segura. Incapaz, como se ha dicho, un lecho estrechado y constreñido por el callejero y caserío de Puerto Lumbreras de evacuar el fabuloso aluvión, la enorme onda de crecida se abatió sobre aquel, arrancó de cuajo hileras de edificios y arrasó cuanto halló a su paso, sembrando muerte y desolación por doquier.

No falta memoria histórica de grandes llenas de la Rambla de Nogalte, como las de «Santa Teresa» (14-15 de octubre de 1879) o la de 22 de mayo de 1948; si bien ninguna de las recordadas lo era como comparable en entidad o, al menos, 
consecuencias a esta de «San Pedro de Alcántara»; sin duda, por ello el lecho ordinario de la Rambla había sido comprimido y reducido por el casco urbano, con inmuebles tempranamente inscritos en el Registro de la Propiedad de Lorca. Sin embargo, no había transcurrido aún medio siglo desde el referido episodio de «San Pedro de Alcántara» (19 de octubre de 1973), décima parte del período de retorno estadísticamente esperado, cuando la Rambla de Nogalte volvió a registrar una salida de magnitud equivalente a la de «San Pedro de Alcántara», la de «San Wenceslao», el 28 de septiembre de 2012; afortunadamente, las obras de acondicionamiento del cauce y defensa realizadas, en su momento, por la Confederación Hidrográfica del Segura, evitaron una catástrofe de parecidas proporciones. Es de resaltar, en primera aproximación, que, al igual que la anterior, esta última gran crecida se produjo en la época o período de máximo riesgo, que transcurre de mediados de septiembre a esas mismas fechas de noviembre; y, además, en circunstancias atmosféricas similares, cercanas a las de 19 de octubre de 1973.

En efecto, las topografías de las superficies de 300 y $500 \mathrm{hPa}$ de los días 27 y 28 de septiembre de 2012 muestran, sobre el Atlántico, entre 25 y $20^{\circ} \mathrm{N}$ y longitudes de 5 y $50^{\circ} \mathrm{W}$ una situación de «bloqueo en omega», en cuya rama, latitudinalmente, descendente se ubica, al suroeste de la Península Ibérica, un

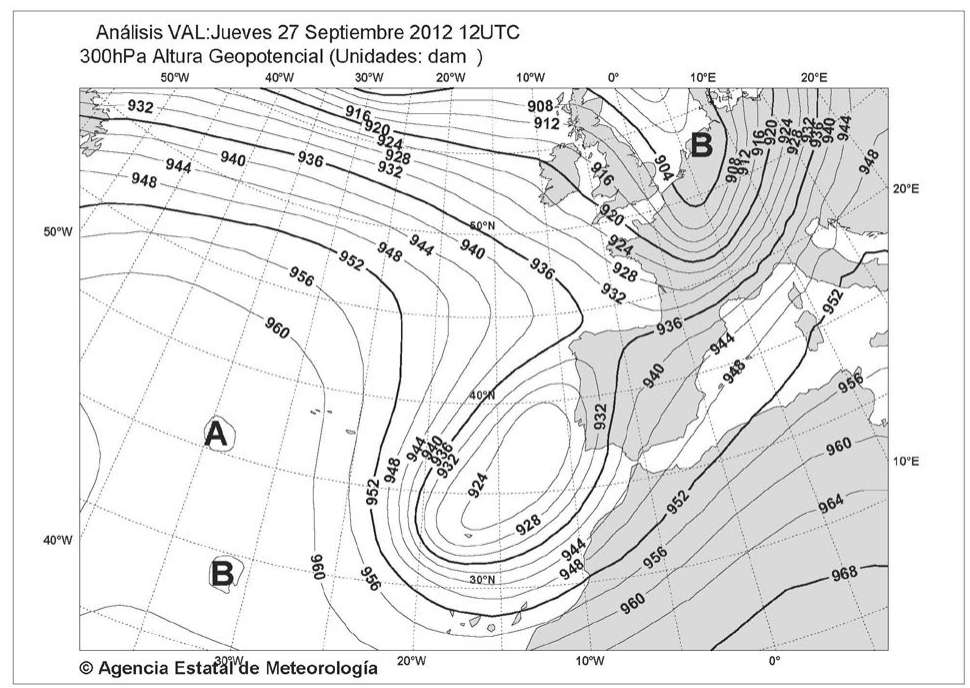

Fig. 6. Débil y poco veloz la corriente en chorro, a menos de $70 \mathrm{~km} / \mathrm{h}$, el bajo índice de circulación transforma la zonal del oeste en meridiana, dibujando crestas y vaguadas adyacentes. En el espacio considerado, a la hora y día indicados, figura una dorsal de bloqueo "en omega", al tiempo que en la vaguada oriental contigua se ha producido el estrangulamiento de tres isohipsas, configurando una depresión fría en altitud, baja desprendida o DANA; si bien, consideradas asimismo la topografía absoluta de $300 \mathrm{~h} \mathrm{~Pa}$, relativa 1000/500 hPa y el análisis en superficie, cabe hablar, sin reserva alguna, de "gota de aire frío" (Kaltluftropfen). 


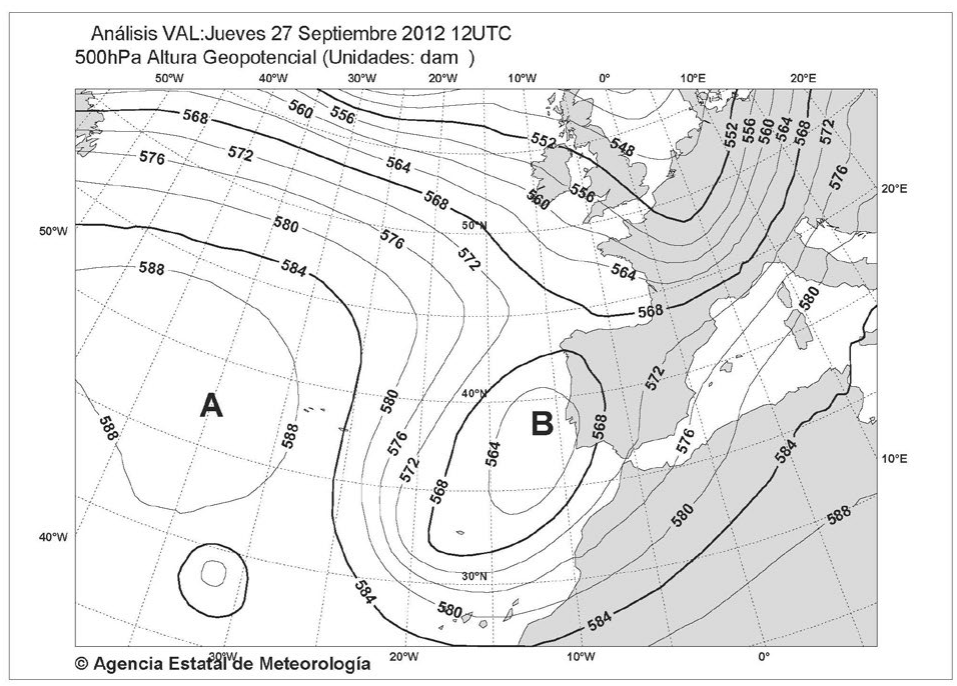

Fig. 7. En la troposfera media, el mapa de altura geopotencial a $500 \mathrm{hPa}$, réplica del descrito en la de $300 \mathrm{hPa}$, registra igualmente el referido bloqueo "en omega" y la susodicha "gota de aire frío", baja desprendida configurada por las isohipsas cerradas de 568 y $564 \mathrm{dm}$.

embolsamiento de aire frío o baja desprendida perfectamente caracterizada, con tres isohipsas, las de 932, 928 y $924 \mathrm{dm}$ estranguladas y cerradas en el seno de una profunda vaguada retrógrada cuyo eje se alarga desde el noroeste de la Península Ibérica al suroeste del archipiélago canario, de manera que el área depresionaria induce, en su sector oriental, una circulación del noreste, que lleva a latitudes subtropicales aire polar continental, con marcada transgresión de isotermas, que traducen la penetración de aire frío, con exageración de gradiente térmico estático en la vertical y la subsiguiente inestabilidad atmosférica.

La baja desprendida, depresión aislada o, en este caso, más específicamente, «gota de aire frío» aparece nítidamente configurada en la topografía absoluta de $500 \mathrm{hPa}$, a las $12 \mathrm{UTC}$, con las isohipsas de 568 y $564 \mathrm{dm}$ cerradas. A la misma hora, como réplica de la situación en altitud, el relieve isobárico o análisis en superficie ofrece un gran anticiclón de bloqueo en el aludido espacio atlántico, con presiones por encima de $1028 \mathrm{hPa}$ en su ápice, y una baja relativa, carente de estructura frontal, al sur de aquél. Sobre el Sureste Ibérico y buena parte de la Península la situación imperante es la de pantano barométrico, con gran distancia entre las isobaras de $1016 \mathrm{hPa}$, correspondiente a una cuña anticiclónica que, a modo de apófisis, prolonga hacia el este, sobre norte de la Península Ibérica y sur de Francia, el anticiclón de bloqueo, y la de 1012, isolínea exterior de una vasta y nada profunda construcción depresionaria, de raigambre térmica, que desborda el Sahara y alcanza Andalucía, Extremadura y tierras portuguesas 


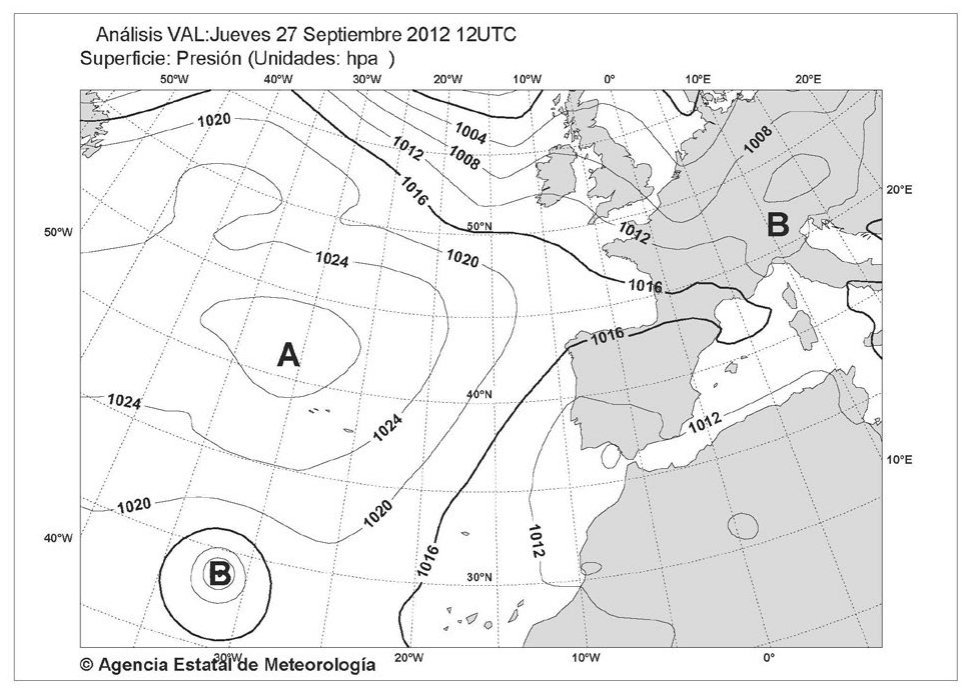

Fig. 8. El análisis en superficie muestra la mayor parte de la Península Ibérica bajo un pantano barométrico, con la isobara 1012 próxima al Sureste. Así pues, presencia de aire relativamente tibio de humedad específica, grado higrométrico, potencial energético e inestabilidad muy elevados, conducido por viento flojo de levante; en suma, condiciones óptimas para su disparo en la vertical.

aledañas. Muy alejadas ambas isobaras, con gradiente horizontal de presión bien exiguo, la circulación sobre el Sureste Ibérico es débil y de rumbo este, favoreciendo el aflujo a dicha área de aire procedente del Mediterráneo Occidental, relativamente cálido, con alta capacidad de retención de vapor de agua, y, por ende, capaz de almacenar la abundante transferencia del mismo desde aguas mediterráneas con isotermas en su superficie de 22 y $24^{\circ} \mathrm{C}$, a las $6.00 \mathrm{~h} \mathrm{UTC}$; la humedad relativa de dicho aire quedaba próxima a la de saturación, de modo que podía ascender, merced a la liberación abundante de energía latente, con reducido gradiente pseudoadiabático desde niveles muy bajos.

Así pues, factores sumamente propicios al disparo en la vertical, hasta la tropopausa, de este aire de procedencia supramediterránea eran los siguientes: en superficie, aire de procedencia mediterránea, con fuerte carga hídrica y elevado potencial energético, de grado higrométrico cercano a la saturación, con gradiente térmico horizontal a su favor, y capaz de evolucionar, desde nivel de mar o reducida altitud, con débil gradiente pseudoadiabático. Junto a ello, se ha destacado la presencia, en las troposferas media y superior de aire anormalmente frío, que exagera los gradientes térmicos estáticos en la vertical; circunstancia esta que, combinada con la ventaja térmica inicial y comportamiento marcadamente pseudoadiabático, con reducido enfriamiento, inferior al de su entorno, del aire ascendente, intensifica la inestabilidad, permitiendo así potentes ascensos, 


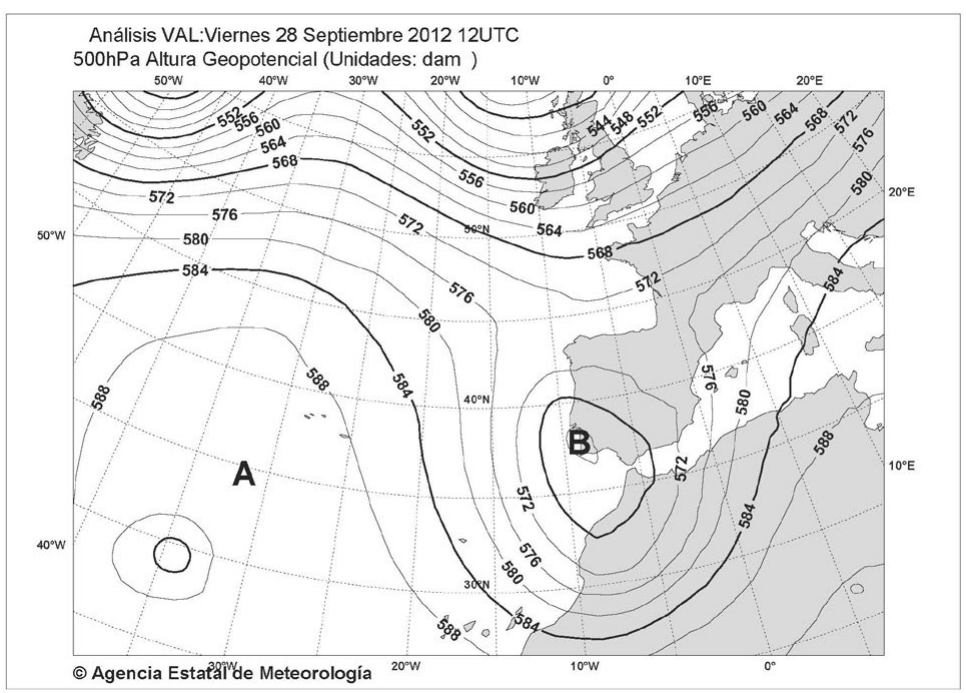

Fig. 9. Respecto de la topografía absoluta de idéntica altura geopotencial $(500 \mathrm{hPa})$ de $27 \mathrm{de}$ septiembre de 12 UTC, esta, veinticuatro horas después, muestra la seclusión de la isohipsa 572 dm y un enderezamiento del eje de la vaguada que sitúa sobre el Sureste Ibérico la divergencia en delta por difluencia que conforma la isohipsa exterior de la baja desprendida y la más interior de la vaguada, con altitudes respectivas de 572 y $576 \mathrm{dm}$. A la hora de potenciar e intensificar los movimientos convectivos, dicho mecanismo se añade al efecto del juego de los gradientes dinámicos (pseudoadiabáticos reducido por liberación de energía latente) y estáticos (exagerados por la irrupción de aire frío en las troposferas media y superior).

que interesan todo el espesor de la troposfera, hasta la tropopausa, que pone término, achatando en yunque sus cimas, a cumulonimbos de 9-10 km de desarrollo vertical. La coincidencia de todos esos factores hicieron posibles, el 28 de septiembre de 2012, fortísimas focalizaciones pluviométricas en la Sierra de las Estancias, sobre la que, durante unas horas, se abrieron, ese día, «las cataratas del cielo». Dicha fecha, afianzada la situación atmosférica de la víspera en los niveles superiores, el Sureste Ibérico quedaba englobado, en superficie, por una vasta construcción depresionaria relativa, que encaminaba hacia el susodicho espacio débil flujo de levante, particularmente idóneo para dispararse en la vertical por la convección forzada que le imponían los relieves montañosos prelitorales. Algunos datos permiten entrever y sintetizar la magnitud e intensidad del episodio pluviométrico: así, la precipitación acumulada en una hora, ese 28 de septiembre, fueron 119,6 mm (13.10 h) en Puerto Lumbreras y 81,6 en el punto S.A.I.H. de la Rambla de Nogalte; en uno y otro caso, notoriamente superiores a los $60 \mathrm{~mm}$ del umbral rojo. Y en cuanto a la precipitación acumulada en 12 horas subía a 212, 0 mm en Puerto Lumbreras (14.40 h) y 160,5 en la cabecera de la Rambla de Nogalte, por encima ambos del umbral naranja (100 mm) y del rojo 


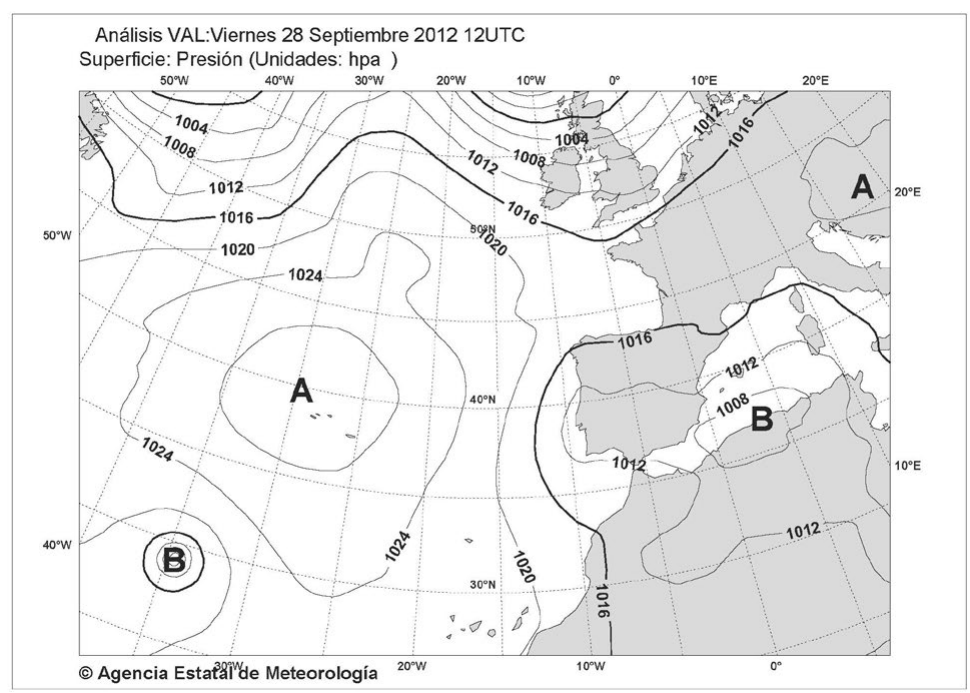

Fig. 10. Al robustecimiento del ascenso por la evolución en altitud entre las 12 UTC del día 27 y la misma hora del 28 , se suma el incremento del aflujo de aire tropical continental en origen que, conducido por viento flojo de levante, ha enjugado su déficit hídrico sobre las tibias aguas mediterráneas, al tiempo que aporta, en forma de polvo sahariano, abundantes núcleos de condensación.

$(180 \mathrm{~mm})$ el primero y próximo el segundo; con todo, ha de tenerse bien presente que, en la superficie vertiente considerada, los condicionamientos orográficos y el flujo de levante ocasionaron focalizaciones pluviométricas extraordinarias, muy probablemente en determinados sectores más copiosas e intensas que las señaladas, necesariamente torrenciales. De subrayar es asimismo que los elevados volúmenes de precipitación se produjeron, esencialmente, en breve tiempo, unas pocas horas. Los hietogramas de los pluviómetros indicados del SAIH en Rambla de Nogalte (Puerto Lumbreras) y Rambla de Nogalte (Lorca) evidencian la aludida concentración horaria, con precipitaciones acumuladas, para el período $08.01 \mathrm{~h}$ de $27-09$ a $02.00 \mathrm{~h}$. de 29.09/2012, de 162,8 y $179,2 \mathrm{~mm}$, con máximas cincominutales respectivas de 17,0 y $6,7 \mathrm{~mm}$.

Acorde con su desmedidos carácter y funcionamiento torrenciales, la Rambla de Nogalte tradujo el colosal diluvio en una descomunal crecida-relámpago, como atestiguan y compendian las evoluciones de niveles y caudales siguientes:

\begin{tabular}{|l|c|c|c|c|c|c|c|c|c|c|c|c|c|}
\hline Hora: & $08: 00$ & $10: 00$ & $12: 00$ & $12: 05$ & $12: 20$ & $12: 25$ & $13: 00$ & $14: 05$ & $14: 40$ & $15: 50$ & $16: 00$ & $16: 10$ & $17: 00$ \\
\hline Nivel(m): & 0,62 & 0,22 & 0,16 & 0,17 & 4,30 & 4,43 & 4,67 & 4,00 & 1,04 & 0,63 & 0,40 & 0,00 & 0,00 \\
\hline $\begin{array}{l}\text { Caudal } \\
\left(\mathrm{m}^{3} / \mathrm{s}\right):\end{array}$ & 0,03 & 13,60 & 6,08 & 7,24 & 2.255 & 2.337 & 2.489 & 2.065 & 279 & 106 & 50 & 0 & 0 \\
\hline
\end{tabular}

Fuente: Confederación Hidrográfica del Segura 


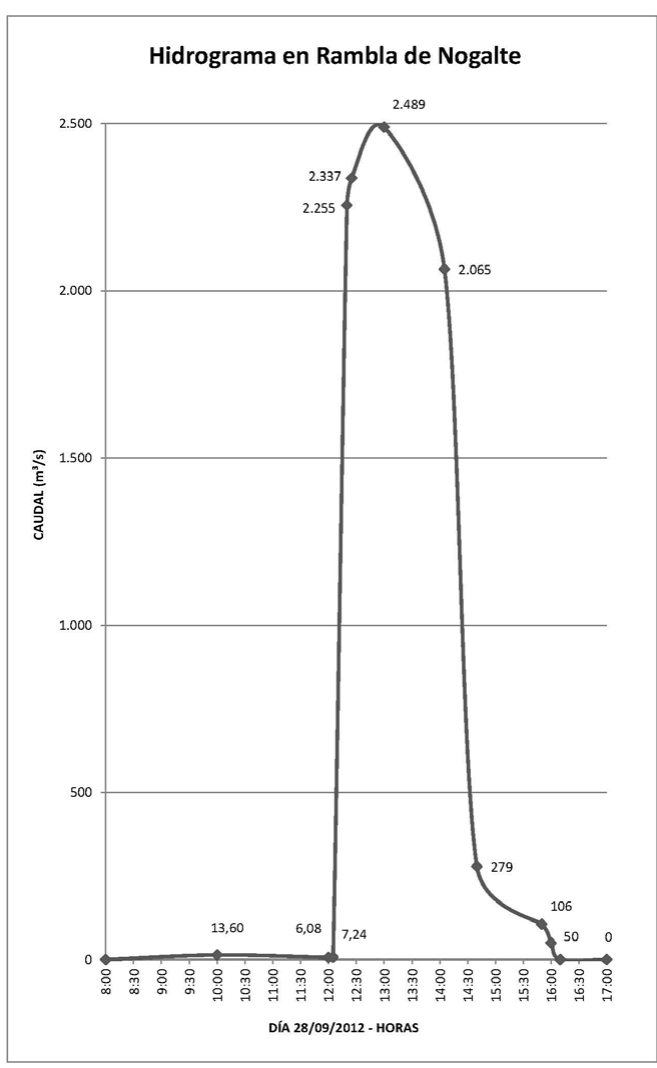

Fig. 11. Hidrograma de la Avenida de San Wenceslao, el 28 de septiembre de 2012, en la Rambla de Nogalte, con el más elevado máximo o punta $\left(2.489 \mathrm{~m}^{3} / \mathrm{s}\right.$, en Puerto Lumbreras) de que hay noticia histórica para este tipo de cursos en la cuenca del Segura. Con 19,89 $\mathrm{hm}^{3}$ circulados en 3 horas, la fabulosa llena resultó de precipitaciones muy copiosas e intensas sobre una reducida cuenca $\left(139 \mathrm{~km}^{2}\right)$ de acendrado funcionamiento sincrónico y torrencial. Rasgos destacables de esta crecidarelámpago prototípica son: súbito y vertiginoso aumento de caudal, y corta duración y rápido descenso de la avenida, pronto concluida.
Los datos anteriores reflejan un ejemplo prototípico de llena súbita, con avenida fulminante, $y$ en vertiginoso ascenso exponencial, que en no más de quince minutos multiplica por 25,3 su calado (de 0,17 a 4,30 m) y por 311,46 su caudal (de 7,24 a $2.255 \mathrm{~m}^{3} / \mathrm{s}$ ), para subir casi a la altura máxima y punta de avenida que, relativamente próximas $\left(4,67 \mathrm{~m} \mathrm{y} 2.489 \mathrm{~m}^{3} / \mathrm{s}\right)$, se alcanzan 40 minutos después, a las 13:00 horas. Otras referencias relevantes constituyen que, entre 12.20 y 14:05 horas, o sea, $1 \mathrm{~h} .40 \mathrm{~m}$, el calado excedió de $4 \mathrm{~m}$ y el caudal de $2.000 \mathrm{~m}^{3} / \mathrm{s}$, para descender 35 minutos después, a las 14:00 h, a $1,04 \mathrm{~m}$ y $279 \mathrm{~m}^{3} / \mathrm{s}$, dejando prácticamente de circular a las 16.10 horas. En suma, el funcionamiento de las ramblas del Sureste Ibérico, intermitente, espasmódico, extremadamente irregular, y sus potentes salidas esporádicas alcanzan condición prototípica en la de Nogalte, que, las horas centrales del 28 de septiembre de 2012, conoció un paroxismo torrencial de violencia y entidad inauditas, superiores incluso a las elevadísimas de la enorme llena de «San Pedro de Alcántara», el

19 de octubre de 1973; solo las actuaciones hidráulicas de la Confederación Hidrográfica del Segura tras esa mortífera crecida, evitaron una calamidad similar. Arquetípico es asimismo el hidrograma de la susodicha exacerbación, en el que las fuertes pendientes de las líneas representativas del vertiginoso ascenso $\mathrm{y}$ del rápido descenso, hasta y desde los umbrales de $2.000 \mathrm{~m}^{3} / \mathrm{s}$ y calado de 
$4 \mathrm{~m}$, mantenidos $1 \mathrm{~h} 45 \mathrm{~m}$, reflejan la naturaleza del fenómeno: brusco, efímero y devastador, intrínsecamente torrencial; el primero de esos trazos sube casi en ángulo recto con el eje de abscisas y cercano al paralelismo con el de ordenadas, prácticamente en la vertical, acorde con el crecimiento exponencial $\mathrm{y}$ vertiginoso del caudal de avenida; bien inclinado aparece también el segundo, en armonía con una finalización acelerada de la llena, cuyo canal se redujo un $86,49 \%$ en poco más de media hora (de 2.065 a 279 $\mathrm{m}^{3} / \mathrm{s}$ ), para cesar sin apenas circulación y altura inferior al centímetro, diez minutos después.

Aguas abajo del casco de Puerto Lumbreras, a la altura de la Venta de Ceferino, el formidable aluvión se bifurcó: la mayor parte se dirigió a la Rambla de Biznaga, y el resto a la de Charcones, que atraviesa, encauzada, el núcleo urbano de Pulpí; esta rambla, luego de recibir la aportación de la de

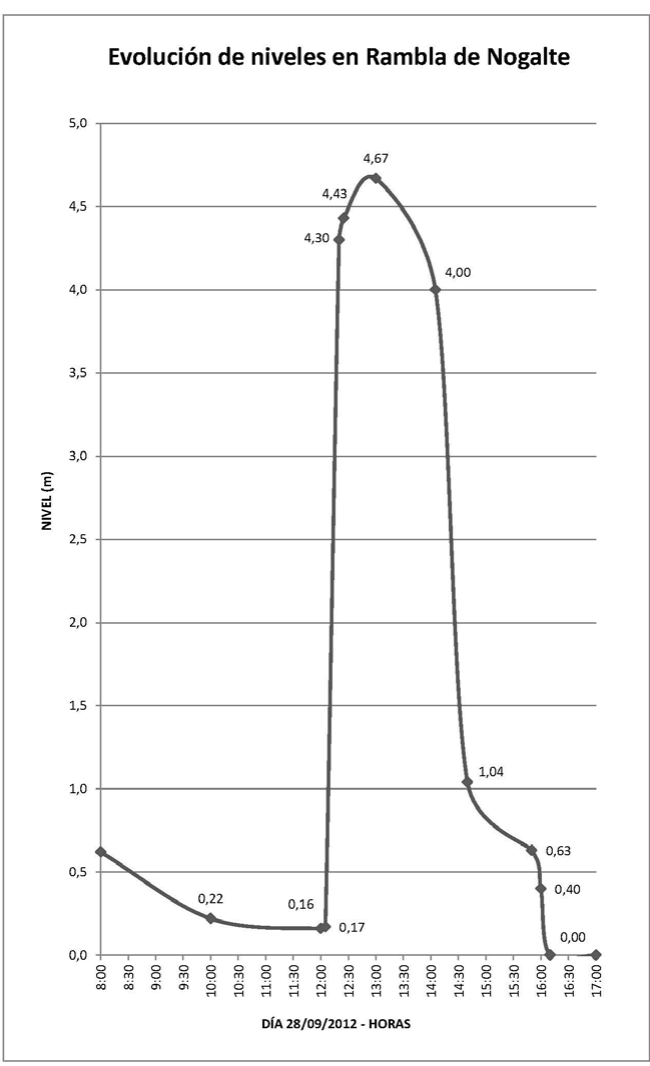

Fig. 12. La evolución de alturas de la llenarelámpago de San Wenceslao en la Rambla de Nogalte conoció una evolución paralela a la del hidrograma, si bien los caudales derivan no solo de la sección mojada sino de las diferentes velocidades del agua en dicha área.

Guazamara, entronca con la de Canalejas, por medio de la cual, cuyas aguas desmadradas ofrecían imponente aspecto en el paraje de Los Lobos, en término de Cuevas de Almanzora, alcanzan este río-rambla almeriense. Por su parte, la crecida que desbordaba la Rambla de Biznaga, incrementada por los caudales de las ramblas del Murciano, Béjar y La Torrecilla, continuó por este curso, conocido también más adelante como Rambla de Purias, y afluyó al Guadalentín al turbión de $616 \mathrm{~m}^{3} / \mathrm{s}$ que bajaba por este, generado, aguas abajo de Puentes; sumadas a dicho turbión las aportaciones de las ramblas de Purias, con diferencia en este caso el de mayor volumen, y Lebor, totalizó una punta de $1.082 \mathrm{~m} / \mathrm{s}$ en el Azud del Paretón (Totana). De ellos, $924 \mathrm{~m}^{3} / \mathrm{s}$ fueron derivados, por la Rambla de las Moreras (Mazarrón), al Mediterráneo; solo 158 m³/s continuaron, 
en el Guadalentín, hasta la presa de laminación del Embalse de José Bautista o Romeral $\left(6 \mathrm{hm}^{3}\right)$, reduciéndose el caudal punta a $60 \mathrm{~m}^{3} / \mathrm{s}$ en el Aforo de Salabosque (Reguerón), a las 20.10 h de ese 28 de septiembre.

\section{DEFENSA DE AVENIDAS: EVACUACIÓN Y CONTROL}

Esencialmente irregular, el régimen pluviométrico del Sureste Ibérico conjuga duras y prolongadas secas con esporádicos diluvios; cuando alguno de estos sucesos resulta particularmente dañino, suele acicatear actuaciones para prevenir o reducir riesgos. Y la llena de 19 de octubre de 1973, la de «San Pedro de Alcántara», en la Rambla de Nogalte, la más mortífera de las avenidas acaecidas en la cuenca del Segura desde la célebre de «Santa Teresa» (14-15 de octubre de 1879), no ha sido, como parece lógico, una excepción, sino todo lo contrario, en un doble nivel: Plan de Defensa de las Avenidas del Segura (1977) y acondicionamiento parcial de la referida rambla, y todo ello en circunstancias políticas y económicas complicadas. Sin duda, la catástrofe ocasionada por la rambla ponía bien de manifiesto que, como afirmaban los ingenieros de la Confederación Hidrográfica del Segura, el problema de las inundaciones en la cuenca revestía aún, mientras no se emprendiese o completase la corrección y control de ramblas y ríos-ramblas, enorme gravedad y peligro. Inmejorables conocedores de la cuestión, el plan de actuaciones necesarias fue concluido por dichos técnicos, bajo la dirección del Ingeniero José Bautista Martín, en 1977; si bien, por motivos financieros, no se llevaría a cabo, con algunas modificaciones, sino a partir de la promulgación del Real Decreto-Ley 4/1987, de 13 de noviembre, (Plan General de Defensa contra inundaciones de la Cuenca del Segura), que dispuso la realización, con carácter urgente, de doce presas en ramblas y ríos-ramblas Pliego y Guadalentín, recrecimiento de la de La Cierva en el ríorambla Mula, ampliación de la derivación del Paretón de Totana para sustraer, en su caso, al Guadalentín hasta $1.200 \mathrm{~m}^{3} / \mathrm{s}$ y, aprovechando una ensilladura en la divisoria de aguas, encaminarlos, por la Rambla de las Moreras, directamente al Mediterráneo, mejora de la conexión artificial Guadalentín-Segura en el Reguerón, canal-aliviadero Argos-Quípar, encauzamiento de la rambla de Minateda y, sobre todo, del propio Segura entre la Contraparada y Guardamar, reduciendo la longitud del curso de 75 a $53 \mathrm{~km}$, y mejorando su capacidad de desagüe. Con ocasión de la Riada de San Wenceslao, la laminación y control de caudales circulantes en el Alto Guadalentín ejercidos por los embalses de cabecera (Valdeinfierno-Puentes IV), Azud-derivación del Paretón y Embalse «José Bautista» funcionaron a la perfección, con total eficacia. Así pues, con el decidido propósito de laminar las avenidas de los ríos-ramblas y ramblas afluentes al Segura, no se planteó, por entonces, la construcción de una presa que controlase las colosales de la Rambla de Nogalte, ni la corrección de su 
cuenca para restringirlas o atenuarlas. Comprensiblemente, la prioridad fue proteger de las temibles y mortíferas embestidas de la Rambla a la población de Puerto Lumbreras, objetivo logrado mediante la construcción, con expropiación de fincas urbanas que invadían el lecho de aquella, de un cauce capaz de conducir hasta $2.500 \mathrm{~m}^{3} / \mathrm{s}$, configurado por poderosos diques laterales o murallones que defienden el tejido urbano adyacente; fue, como se ha dicho, esta intervención hidráulica la que evitó, casi cuatro décadas después, la repetición de la catástrofe de 1973: la extraordinaria llena de San Wenceslao, mayor aún que la de San Pedro de Alcántara -con puntas respectivas de 2.489 y 1.974 $\mathrm{m}^{3} / \mathrm{s}-$, llenó a tope el enorme canal, sin desbordarlo, Fue, pasado el núcleo de Puerto Lumbreras, cuando las aguas fangosas, enteramente desmadradas, horras de toda contención, inundaron, ocasionando víctimas y cuantiosos daños materiales, las pedanías de El Esparragal-Estación, Puerto Adentro-Góñar y Cabezo de la Jara. También los estragos y pérdidas fueron de consideración en tierras lorquinas aledañas, anegadas por las crecidas de las ramblas del Murciano, Béjar y Torrecilla, tributarias, como la de Nogalte, por la margen izquierda, de la Rambla de Biznaga; el impetuoso aluvión de la Rambla de Béjar derrumbó el puente de la Autovía A-7 que la cruza.

El episodio hizo bien patente la urgente necesidad de controlar estos monstruosos aparatos torrenciales y corregir sus cuencas de recepción, al objeto de abortar o, al menos, atenuar sus formidables crecidas-relámpago, fruto de una veloz acumulación sincrónica de caudales que, además, al proporcionarles competencias y límites de carga elevadísimos, favorecen el transporte de ingentes aportaciones sólidas; la defensa frente a estos formidables aluviones reclama una serie de actuaciones conjuntas e interrelacionadas, que incluyen diques de retenida, presas de laminación y reforestaciones. Encauzado el canal de desagüe de la Rambla de Nogalte a su paso por el núcleo de Puerto Lumbreras, que salvaguarda el caso urbano, las actuaciones en la cabecera han comenzado, con la construcción de diques de retenida, a raíz de la llena de San Wenceslao, la mayor $\left(2.489 \mathrm{~m}^{3} / \mathrm{s}\right)$ de que hay noticia histórica en las ramblas de la cuenca del Segura. Fueron once los diques de retenida construidos, durante 2013, por la Confederación Hidrográfica del Segura en la cuenca de recepción torrencial de la rambla, con objto de reducir los caudales líquidos y sólidos circulantes, minorando así las puntas de avenida; capaces de frenar caudales punta, según emplazamientos y cabidas, entre 7 y $60 \mathrm{~m}^{3} / \mathrm{s}$, con altura de $9 \mathrm{~m}$ y cuencos de 10 a 13 m de ancho, mientras los desarrollo en coronación van de 65, en el más estrecho de los ramblizos, a $110 \mathrm{~m}$ del más amplio. A estos once diques iniciales, cuyo presupuesto, cofinanciado por la Unión Europea, ascendió en total a 4.024.000 euros, se añadieron luego otros tres, ubicados respectivamente en el Barranco del Caballete y ramblas de Oliverica y Losilla, también con altura de $9 \mathrm{~m}$ y presupuesto base de 1.537 .645 euros; complementariamente, se plantaron 
árboles y arbustos para minorar la erosión de las superficies vertientes. Otros seis diques, también en la cabecera de la Rambla de Nogalte, fueron levantados con posterioridad. Así pues, un total de 20 diques de retenida para evitar el rápido ascenso de la avenida y reducir el aporte sólido. Actuaciones de más entidad constituyen las presas proyectadas en la propia Rambla de Nogalte y en las de Béjar y Torrecilla, tributarias todas ellas de la Rambla de Biznaga.

El serio problema que afecta y amenaza estas infraestructuras hidráulicas es el de su rápido terraplenamiento o colmatación, dada la fuerte agresividad erosiva del clima semiárido del raigambre mediterránea y verano seco de filiación subtropical, en especial porque a dicho estío sigue, en los meses tardoestivales, de mediados de septiembre a idénticas fechas de noviembre, el período de máximo riesgo de diluvios; aguaceros estos muy copiosos e intensos que, sobre materiales detríticos o deleznables a los que el ambiente seco ha restado compacidad, apenas protegidos por una vegetación rala y, las más de las veces, raquítica, ocasionan fortísimas ablaciones, transportadas por escorrentías concentradas con cargas límite muy cuantiosas.

Para que las infraestructuras hidráulicas de defensa de avenidas construidas o previstas resulten viables y razonablemente duraderas, es preciso que vayan acompañadas de medidas eficaces de lucha contra las erosiones areolar y lineal; si no es así, quedarían cegadas bien pronto por el ingente volumen de arrastres.

\section{Algunas CONSIDERACiones Finales}

Los acontecimientos meteorológicos singulares que, a favor de la focalización ocasional de precipitaciones en la Sierra de las Estancias y del excepcional aparato torrencial que, con inusitada rapidez, las concentra, han deparado las mayores llenas que se recuerdan en la Rambla de Nogalte: son, por orden cronólogico, los acaecidos el 22 de octubre de 1948, 19 de octubre de 1973 y 28 de septiembre de 2012. Como se ve, los tres tardoestivales y correspondientes al período con máximo riesgo de diluvios en el Sureste Ibérico, los dos meses que transcurren desde mediados de septiembre, con ápìce en octubre. Las tres situaciones atmosféricas de referencia presentan notorias similitudes y denominador común en los aspectos básicos.

Así, por lo que hace a los patrones de variabilidad de baja frecuencia, es decir, en el caso que nos ocupa, las oscilaciones del Atlántico Norte (NAO), Mediterráneo (MO) y Mediterráneo Occidental (WeMO), los índices correspondientes, atendidos análisis en superficie y circulación superior según corresponda, son marcadamente negativos, acordes con situaciones de marcada baroclinia y flujos de componente este, vientos llovedores, en las susodichas configuraciones isobáricas. 
Debiera, empero, ser obvio que la referencia, laxa y poco comprometida, a la DANA o, la más específica académicamente a la «gota de aire frío», por sí solas no justifican, explican o caracterizan ninguno de los diluvios tardoestivales en el Sureste Ibérico, y en especial los de mayor entidad, como los tres referidos. Es de resaltar que una y otra no son sinónimos de precipitaciones copiosas e intensas, ni estas las tienen por causas necesarias; y, en relación con ello, conviene retener un dato significativo: la mayor frecuencia de las irrupciones de aire frío en las troposferas superior y media, que configuran las vaguadas en cuyos senos pueden formalizarse embolsamientos, o sea, las depresiones aisladas o desprendidas de aire frío en altitud, corresponde a finales de invierno; en cambio, como se ha reiterado, el período de máximo riesgo para aguaceros copiosos de gran intensidad horaria transcurre, como se ha iterado, entre mediados de septiembre y primera mitad de noviembre, con culmen en octubre. Se hace patente así un notorio desfase cronológico entre ambos fenómenos, y ello invita a pensar que en los diluvios otoñales concurren otros factores o elementos. La inequívoca concentración de estas manifestaciones pluviométricas paroxísmicas en otoño no es casual, sino consecuencia de una combinación favorable de riesgo potencial y mecanismos que lo catalizan y materializan. El dato de base, requisito imprescindible en los tres acontecimientos analizados, y en cualquier otro de parecida naturaleza, consiste en la advección de masas de aire relativamente cálido, con elevados grado higrométrico, relación de mezcla y potencial energético, y abundantes núcleos de condensación o engelamiento, que evolucionan con gradientes pseudoadiabáticos reducidos desde escasa altitud, y alimentan poderosas corrientes convectivas, generadoras de gigantescas nubes de desarrollo vertical hasta el límite de la tropopausa.

El detonante habitual de las mismas son las invasiones de aire frío en los niveles superiores, con una u otra configuración (vaguada meridiana, retrógada, baja desprendida o depresión aislada, «gota de aire frío», desarrollo ciclogenético, sistema convectivo de mesoscala, etc.), incrementando los gradientes térmicos en la vertical y auspiciando el funcionamiento de divergencias por difluencia en altitud. Sin embargo, es obligado no olvidar los análisis en superficie, diversos (áreas depresionarias relativas, pantanos barométricos, bordes meridionales de anticiclones de bloqueo, etc.), pero coincidentes en isobaras espaciadas, gradientes horizontales de presión reducidos e inductores de flujos del este que transportan el aire de procedencia mediterránea, a cuyas expensas se generan los susomentados diluvios. Así, el ensamblaje e interrelación de situaciones en superficie y altitud propicias procuran, esporádicamente, la conjunción adecuadas de mecanismos y elementos causantes de estos aguaceros excepcionales por su abundancia e intensidad, con sus secuelas de avenidas, desbordamientos y anegaciones. 


\section{BIBLIOGRAFÍA}

Capel Molina, J.J. (1974): «Génesis de las inundaciones de octubre de 1973 en el Sureste de la Península Ibérica», Cuadernos Geográficos, n. ${ }^{\circ}$ 4, págs. 69-83.

Confederación Hidrográfica del Segura (2013): «Las obras hidráulicas y la defensa frente a las inundaciones. Experiencia de la Riada de San Wenceslao en la Cuenca del Segura, Septiembre 2012», Jornada Técnica, 24 de enero de 2013, https://www.chsegura.es/export/descargas/cuenca/infraestructuras/seprem/docsdescarga/Seprem_MARodenas-2.pdf

Conesa García, C. (1985): «Inundaciones en Lorca (Murcia): riesgo y expectación», Papeles de Geografía Física, n. ${ }^{\circ} 10$, págs. 33.47.

Couchoud Sebastiá, R. y SÁnchez Ferlosio, R. (1965): Hidrología histórica del Segura, 2. ${ }^{a}$ ed., Murcia, Colegio de Ing. de Caminos, Canales y Puertos, 1984, 104 págs.

GALlego JimÉnez, F. (1996): Situaciones de flujo mediterráneo y precipitaciones asociadas. Aplicación a la predicción cuantitativa en la cuenca del Segura, Murcia, Universidad de Murcia, 412 págs.

Gil Meseguer, E., Pérez Morales, A. y Gómez Espín, J. M.a (2012): «Precipitaciones y avenidas del 28 de septiembre de 2012 en el cuadrante suroccidental de la cuenca del Segura (Municipios de Lorca, Puerto Lumbreras y Pulpí)», Papeles de Geografía, n. ${ }^{\circ}$ 55-56, págs. 75-94.

Gil OlcinA, A. (2000): "Acondicionamiento hidráulico y desnaturalización del río Segura», Ería, n. ${ }^{\circ}$ 51, págs. 45-59.

Gil Olcina, A. (2004): «La Región Climática del Sureste Ibérico» Aridez, Salinización y Agricultura en el Sureste Ibérico, Fund. Ramón Areces y Fund. Inst. Euromediterráneo de Hidrotecnia, págs. 13-35.

Gil Olcina, A. y Morales Gil, A., ed. (1989): Avenidas fluviales e inundaciones en la cuenca del Mediterráneo, Alicante, Inst. Universitario de Geografía y CAM, 586 págs.

Gómez Espín, J. M. (2004): Aprovechamiento integral del agua en la Rambla de Nogalte (Puerto Lumbreras-Murcia), Murcia, Universidad de Murcia, 190 págs.

López Bermúdez, F. (1973): La Vega Alta del Segura. Clima, Hidrología y Geomorfología, Murcia, Universidad de Murcia, 288 págs.

Navarro Hervás, F. (1991): El Sistema Hidrográfico del Guadalentín, Cuadernos Técnicos n. ${ }^{\circ}$ 6, Consejería de Política Territorial, Obras Públicas y Medio Ambiente, Murcia, 256 págs.

Ródenas CAÑAda, M.A. (2013): «La Riada de San Wenceslao en la Cuenca del Segura, 28 de septiembre 2012», 25 de marzo de 2013, http:/www.iahr.org/uploadedfiles/ userfiles/files/IAHR_CEDEX_MARodenas.pdf 